\title{
Characteristics and Pharmacological Treatment Options of Delirium Patients Treated at Sanglah Central General Hospital
}

\author{
Ni Ketut Sri Diniari \\ Universitas Udayana, Denpasar, Bali, Indonesia \\ Corresponding author email: sridiniari@ymail.com \\ Luh Nyoman Alit Aryani \\ Universitas Udayana, Denpasar, Bali, Indonesia
}

\begin{abstract}
Delirium is a syndrome characterized by disturbances of consciousness and cognition that occur acutely and fluctuate. Delirium can be caused by general medical conditions, drug users, sensory disturbances, polypharmacy, etc. The etiology of delirium is diverse and non-specific. The preference of pharmacological therapy in delirium is still a debate. Descriptive research with the retrospective cross-sectional method, using secondary data in medical records at the Sanglah Central General Hospital Denpasar for the period January 1, 2020, to December 31, 2020. Patients who were consulted were 166 people, with sex 57 people (34.3\%) and 109 women (65.7\%). The incidence of delirium in adults (20-59 years old) and elderly (age 60 years) is the highest with $51.2 \%$ and $45.1 \%$ respectively. One-third of 45 people (37.2\%) had overlapping dementia. Most of the 142 people (85.5\%) were experiencing significant life stress. The most common type of delirium was hyperactive delirium (74\%). The underlying disease of delirium varies such as the cause of infection (24.1\%), intracranial process (19\%), malignancy $18.1 \%$, cardiovascular (10.1\%), endocrine disorders,(7.8\%), kidney disorders (6\%), and others in small percentages.
\end{abstract}

Keywords---characteristics, delirium, pharmacological, syndrome, treatment options

\section{Introductions}

Delirium is a syndrome characterized by disturbances of consciousness and cognition that occur acutely and fluctuate. Delirium can be caused by general medical conditions, old age, polypharmacy, sensory disturbances, or drugs intoxication/withdrawal (Sadock et al., 2015). The etiology of delirium is diverse and non-specific. Pharmacological therapy in delirium condition is still a matter of debate. In some studies, antipsychotic administration is effective at reducing the length of treatment and lowering the incidence of death in patients with delirium. Pharmacological therapy is mainly given to hyperactive delirium to improve the motor condition of rowdy patients so that patients can be more cooperative in undergoing treatment (Nogueira et al., 2013; Sastroasmoro \& Ismael, 2011). Haloperidol is an antipsychotic commonly used in delirium therapy. But the use of haloperidol can affect heart rhythm which can cause death due to heart rhythm disorders. The use of haloperidol can also cause cognitive decline. Therefore, risperidone is also often used as the therapy of choice in delirium (Lucchetti, 2018). On one side, both atypical antipsychotics and benzodiazepines can affect the metabolic condition and consciousness of the patient, so it will be a concern when it comes to using them. With a wide variety of antipsychotic therapy options in delirium conditions, this study was conducted to find out the characteristics of patients and pharmacological therapies that are most often used in delirium patients (Cummings et al., 1998; Davis et al., 2013; Wan \& Chase, 2017). 


\section{Method}

This study is descriptive with a retrospective latitude cut method (cross-sectional used secondary data in the form of medical records to find out the character description and choice of delirium pharmacological therapy at Sanglah Central General Hospital Denpasar (First, 2013; Mueller et al., 2017; Burry et al., 2019). The target population of this study was all patients with delirium diagnoses within one year from January 1, 2020, to December 31, 2020. Samples were taken consecutively in elderly patients with delirium who were treated in an elderly-only treatment ward at Sanglah Central General Hospital Denpasar with a total of 166 samples.

\section{Results}

Characteristics of the subjects were patients who experienced delirium from January 1 to December 31, 2020, which were consulted to the psychiatric department as many as 166 people, with the proportion of male 57 people (34.3\%) and female 109 people (65.7\%) (Witlox et al., 2010; Zipser et al., 2019; Baller et al., 2020). The incidence rate in adult delirium patients (20-59 years) and the elderly (age $\geq 60$ years) is the most experienced delirium with rates of $51.2 \%$ and $45.1 \%$.

Table 1

Characteristics of delirium patients during the period of January 1 to December 31, 2020

\begin{tabular}{lll}
\hline Variable & Frequency & $\%$ \\
\hline Gender & & \\
Male & 57 & 34.3 \\
Female & 109 & 65.7 \\
Age & & \\
Child (2-10) & 2 & 1.2 \\
Adolescent (11-19) & 4 & 2.4 \\
Adulr (20-59) & 85 & 51.2 \\
Elderly ( $\geq 60)$ & 75 & 45.1 \\
Dementia & & \\
Present & 45 & 37.2 \\
No & 121 & 62.8 \\
Life stress & & \\
Present & 142 & 85.5 \\
No & 24 & 14.5 \\
Delirium Type & & \\
Hyperactive & 123 & 74.1 \\
Hypoactive & 12 & 7.2 \\
Mixed & 31 & 18.7 \\
Comorbidity & & \\
Infection & 40 & 24.1 \\
Intracranial & 32 & 19 \\
Malignancy & 30 & 18.1 \\
Cardiovascular & 18 & 10.1 \\
Endocrine disorder & 13 & 7.8 \\
Kidney disorder & 10 & 6.6 \\
Trauma & 8 & 4.8 \\
Electrolyte & 5 & 3 \\
Others & 10 & 6.6 \\
\hline & & \\
& &
\end{tabular}

The prevalence of delirium superimposed on dementia was $37.2 \%$, while $85.5 \%$ of delirium patients were currently having life stress. The most common type of delirium was hyperactive delirium (74\%). The underlying or co-morbid diseases of delirium were varied, such as infection (24.1\%), intracranial (19\%), malignancy (18.1\%), cardiovascular $(10.1 \%)$, endocrine disorder (7.8\%), kidney disorder (6\%), and many others in small percentages, such as trauma, electrolyte abnormalities, autoimmune disease, and other diseases (Ospina et al., 2018; Velásquez-Tirado et al., 
2021; Mustika \& Sudiantara, 2019). (Table 1). The symptoms of delirium patients which were the reason patient consulted to the psychiatric department, early-type insomnia 38 (23\%), mixed type insomnia 138 (77\%), anxiety/increased psychomotor (79.5\%), disorientation (72\%), hallucinations (28\%), fluctuating impaired consciousness $(53 \%)$, emotional changes with a balanced proportion between irritable, dysphoric, and apathetic (Table 2).

Table 2

Symptoms of consulted delirium patients

\begin{tabular}{lll}
\hline Symptoms & Frequency & $\%$ \\
\hline Consciousness & & \\
$\quad$ Fluctuating & 88 & 53 \\
$\quad$ Clouding & 78 & 47 \\
Disorientation & 120 & 72 \\
Hallucination & 46 & 28 \\
Emotional changes & & \\
$\quad$ Irritable & 58 & 34.9 \\
$\quad$ Dysphoric & 52 & 31.3 \\
$\quad$ Apathetic & 56 & 33.8 \\
Sleep disorders & & \\
(insomnia) & & \\
$\quad$ Early type & 38 & 23 \\
$\quad$ Mixed type & 128 & 77 \\
Increased psychomotor & 132 & 79.5 \\
Decreased psychomotor & 34 & 20.5 \\
\hline
\end{tabular}

The most common pharmacological therapy used in the treatment of delirium patients at Sanglah Central General Hospital Denpasar is using antipsychotic Haloperidol for as many as 103 people (78\%), in addition to 2 other types of antipsychotics, Risperidone and Olanzapine (Maldonado, 2008; Serafim et al., 2015; Sergeev et al., 2021). The administration of Haloperidol is $76 \%$ intraoral and $24 \%$ by injection, with doses of $0.5-0.75 \mathrm{mg}(60 \%)$, the rest varies with a maximum dose of $5 \mathrm{mg}$, the frequency of administration every 24 hours (53\%) and every 12 hours as much as $47 \%$. (Table 3 ).

Table 3

Pharmacological therapy of choice in delirium patients

\begin{tabular}{lll}
\hline Pharmacological Therapy & Frequency & $\%$ \\
\hline Haloperidol & 103 & 78 \\
Dose & & \\
$0.25-0.75 \mathrm{mg}$ & 62 & 60.2 \\
$1.25-2.5 \mathrm{mg}$ & 31 & 30.1 \\
$5 \mathrm{mg}$ & 10 & 9.7 \\
Administration & & \\
Intra oral & 78 & 76 \\
Injection & 25 & 24 \\
Frequency & & \\
Every 12 hours & 55 & 53 \\
Every 24 hours & 48 & 47 \\
Risperidone & 17 & 13 \\
Dose & & \\
$\quad$ mg & 17 & 100 \\
Administration & & \\
Intra oral & 17 & 100 \\
Injection & 0 & 0 \\
Frequency & & \\
\hline
\end{tabular}




\begin{tabular}{lll}
\hline Every 12 hours & 3 & 18 \\
Every 24 hours & 14 & 82 \\
Olanzapine & 12 & 9 \\
Dose & & \\
$2.5 \mathrm{mg}$ & 9 & 75 \\
$5 \mathrm{mg}$ & 3 & 25 \\
Administration & & \\
Intra oral & 12 & 100 \\
Injection & 0 & 0 \\
Frequency & & 8 \\
Every 12 hours & 1 & 92 \\
Every 24 hours & 11 & \\
\hline
\end{tabular}

\section{Discussion}

\section{Characteristics of delirium patients}

From data of medical records taken from January 1 to December 31, 2020, the characteristics of delirium patients were female, adult, and elderly age. Delirium is mostly acquired in old age, and males (Pérez-Ros \& MartínezArnau, 2019). The prevalence of delirium, in general, is $0.4 \%$ at age 18 and older, $1.1 \%$ at age 55 and older, and $13 \%$ at age 85 and older. About $10-30 \%$ are found in patients in the inpatient ward showing symptoms of delirium, and $30-40 \%$ at the age of over 65 years (Lee, 2020). In this study more elderly adults and elderly patients, and women who experienced delirium. This result was affected by the composition of the elderly population who were occupied by more women than men.

The presence of dementia often coincides with the incidence of delirium which the leading cause of dementia is Alzheimer's dementia (60-80\%), followed by vascular dementia (5-10\%), frontotemporal dementia (5\%), Lewy-body dementia (3\%), and other causes dementia. The presence of cognitive impairment with age, accompanied by many physical diseases, and polypharmaceuticals that trigger the incidence of delirium and increased mortality (Reynish et al., 2017). Stress was experienced by most delirium patients who are treated, this is in accordance with the concept of psychopathology the emergence of mental disorders including organic mental disorders affected by multi factors, bio-psycho-social-culture. Problems or psychosocial stress also affect the symptoms of delirium. Unresolved conflicts in the subconscious mind will aggravate the symptoms of delirium (Kourkouta et al., 2015; Lucchetti, 2018).

The most common type of delirium is hyperactivity that is often consulted. Emotional and behavioral disorders in the inpatient ward will interfere with the caring of patients and the environment. The symptoms of most delirium patients are complaints of difficulty to sleep, anxiety/increased psychomotor, not recognizing family (disorientation), and hallucinations are often the reason other expertise consult, in addition to caregiver complaints who are worried or overwhelmed with changes in emotions and behavior experienced by delirium patients (Lauretani et al., 2020). The incidence of hypoactive delirium and mixed type is more numerous but often goes undetected because it is covered by passive/hypoactive symptoms, the presence of physical diseases that trigger patient weakness (Bennett, 2019).

\section{Pharmacological therapy of choice in delirium patients}

No pharmacological therapy has been approved by the Food and Drug Administration (FDA) as a preventive or delirium therapy. The condition led some studies and clinicians to use antipsychotics and alpha 2 agonists on pharmacological approaches because both types of agents are in the clinical trial stage. The use of antipsychotics is still controversial, especially on delirium symptoms with paranoid, psychotic, increased psychomotor. So as the use of benzodiazepines, ramelteon, diphenhydramine, is not recommended because it can aggravate the symptoms of delirium (Thom et al., 2019).

Haloperidol is an antipsychotic that is often used because it effectively overcomes agitation and psychotic symptoms because it works as a dopamine D2 receptor antagonist. Haloperidol is a top choice and has advantages over other antipsychotics as it is available in oral, intramuscular, and intravenous formulas, and has a low risk of sedation and hypotension (Cerveira et al., 2017; Thom et al., 2019). The administration of Haloperidol with low doses, and if needed only by paying attention to some side effects such as extrapyramidal syndrome, heart rhythm 
disorder, QT prolongation, bradycardia. The principle of delirium's main treatment is to overcome the main underlying cause of delirium (Sadock et al., 2015).

Some studies show that atypical antipsychotics such as Olanzapine, Risperidone, and Quetiapine have the same efficacy as Haloperidol in treating delirium. Atypical antipsychotics may also improve cognitive function with a lower incidence of side effects than Haloperidol. When delirium patients also have Parkinson's or Lewy-body dementia, it is recommended to use atypical antipsychotics. Some studies suggest discontinuing antipsychotic administration when delirium symptoms improve, but some suggest a gradual reduction in doses over 1 week of symptom-free (Girard et al., 2010).

In this study, the most used antipsychotic was Haloperidol with small doses by intraoral administration. Some cases were given by injection in a rowdy emergency that is at risk of falls or injury and is usually only given at the beginning of therapy. Atypical antipsychotic Risperidone and Olanzapine were administered in small doses in cases of delirium accompanied by anxiety, emotional disorders, and difficulty sleeping (Inouye et al., 2014; Seitz \& Gill, 2009; Vilke et al., 2012). The atypical antipsychotic is avoided in cases with metabolic disorders such as Diabetes Mellitus or with stroke because it may aggravate the physical illness. Even if needed, it will be only temporary and immediately stopped when the patient is calm. The administration of pharmacological therapy should be combined with nonpharmacological therapy to accelerate the improvement of delirium symptoms, so that could reduce the use of pharmacological therapy (Juraj \& Kuhn, 2021).

\section{Research limitation}

This study is a descriptive study using secondary data from the medical record of patients, where the data obtained is limited to characteristics and pharmacological therapies (Schwartz \& Masand, 2002; Michaud et al., 2007; Engel \& Romano, 1959). In research with clinical trials or case-control methods, the effectiveness of non-pharmacological therapy and pharmacological therapy can be compared, as well as the choice of more effective therapy as the main therapy for delirium can be found.

\section{Conclusion}

Characteristics of delirium patients treated at Sanglah Central General Hospital are adults- elderly; female; one-third with dementia; having stress; most delirium hyperactive type; with medical conditions: infection, malignancy, cardiovascular; and most symptoms consulted are with sleep disorders, increased psychomotor, and emotional

changes. The choice of pharmacological therapy in treating delirium is to use the most antipsychotics is Haloperidol and a small percentage with Risperidone and Olanzapine.

\section{References}

Baller, E. B., Hogan, C. S., Fusunyan, M. A., Ivkovic, A., Luccarelli, J. W., Madva, E., ... \& Smith, F. A. (2020). Neurocovid: Pharmacological recommendations for delirium associated with COVID-19. Psychosomatics, 61(6), 585-596. https://doi.org/10.1016/j.psym.2020.05.013

Bennett, C. (2019). Caring for patients with delirium. Nursing2020, 49(9), 17-20.

Burry, L., Hutton, B., Williamson, D. R., Mehta, S., Adhikari, N. K., Cheng, W., ... \& Rose, L. (2019). Pharmacological interventions for the treatment of delirium in critically ill adults. Cochrane Database of Systematic Reviews, (9).

Cerveira, C. C. T., Pupo, C. C., Santos, S. D. S. D., \& Santos, J. E. M. (2017). Delirium in the elderly: A systematic review of pharmacological and non-pharmacological treatments. Dementia \& neuropsychologia, 11(3), $270-275$.

Cummings, J. L., Coffey, C. E., Duffy, J. D., Lauterbach, E. C., Lovell, M., Malloy, P. F., ... \& Salloway, S. (1998). The clinician-scientist in neuropsychiatry: a position statement from the Committee on Research of the American Neuropsychiatric Association. The Journal of neuropsychiatry and clinical neurosciences, 10(1), 1-9.

Davis, D. H., Kreisel, S. H., Terrera, G. M., Hall, A. J., Morandi, A., Boustani, M., ... \& Brayne, C. (2013). The epidemiology of delirium: challenges and opportunities for population studies. The American Journal of Geriatric Psychiatry, 21(12), 1173-1189. https://doi.org/10.1016/j.jagp.2013.04.007

Engel, G. L., \& Romano, J. (1959). Delirium, a syndrome of cerebral insufficiency. Journal of chronic diseases, 9(23), 260-277. https://doi.org/10.1016/0021-9681(59)90165-1

First, M. B. (2013). Diagnostic and statistical manual of mental disorders, and clinical utility. The Journal of nervous and mental disease, 201(9), 727-729. 
Girard, T. D., Jackson, J. C., Pandharipande, P. P., Pun, B. T., Thompson, J. L., Shintani, A. K., ... \& Ely, E. W. (2010). Delirium as a predictor of long-term cognitive impairment in survivors of critical illness. Critical care medicine, 38(7), 1513.

Inouye, S. K., Westendorp, R. G., \& Saczynski, J. S. (2014). Delirium in elderly people. The Lancet, 383(9920), 911922. https://doi.org/10.1016/S0140-6736(13)60688-1

Juraj, K., \& Kuhn, J. (2021). SOP: treatment of delirium. Neurological Research and Practice, 3(1).

Kourkouta, L., Iliadis, C., \& Monios, A. (2015). Psychosocial issues in elderly. Progress in Health Sciences, 5(1), 232-237.

Lauretani, F., Bellelli, G., Pelà, G., Morganti, S., Tagliaferri, S., \& Maggio, M. (2020). Treatment of delirium in older persons: what we should not do!. International journal of molecular sciences, 21(7), 2397.

Lee, J. (2020). Risk Factors for Nursing Home Delirium: A Systematic Review. Journal of Korean Gerontological Nursing, 22(1), 75-83.

Lucchetti, A., Barcelos-Ferreira, R., Blazer, D. G., \& Moreira-Almeida, A. (2018). Spirituality in geriatric psychiatry. Current opinion in psychiatry, 31(4), 373-377.

Maldonado, J. R. (2008). Delirium in the acute care setting: characteristics, diagnosis and treatment. Critical care clinics, 24(4), 657-722. https://doi.org/10.1016/j.ccc.2008.05.008

Michaud, L., Büla, C., Berney, A., Camus, V., Voellinger, R., Stiefel, F., \& Burnand, B. (2007). Delirium: guidelines for general hospitals. Journal of psychosomatic research, 62(3), 371-383. https://doi.org/10.1016/j.jpsychores.2006.10.004

Mueller, C., Thompsell, A., Harwood, D., Bagshaw, P., \& Burns, A. (2017). Mental health in older people: a practice primer. Leeds: NHS England and NHS Improvement.

Mustika, I. W., \& Sudiantara, K. (2019). Effects of health promotion with family approaches on blood pressure and headache toward elderly. International Journal of Health Sciences, 3(3), 8-16. https://doi.org/10.29332/ijhs.v3n3.344

Nogueira, V., Lagarto, L., Cerejeira, J., Renca, S., \& Firmino, H. (2013). Improving quality of care: focus on liaison old age psychiatry. Mental health in family medicine, 10(3), 153.

Ospina, J. P., King IV, F., Madva, E., \& Celano, C. M. (2018). Epidemiology, mechanisms, diagnosis, and treatment of delirium: a narrative review. Clinical Medicine and Therapeutics (CMT).

Pérez-Ros, P., \& Martínez-Arnau, F. M. (2019). Delirium assessment in older people in emergency departments. A literature review. Diseases, 7(1), 14.

Reynish, E. L., Hapca, S. M., De Souza, N., Cvoro, V., Donnan, P. T., \& Guthrie, B. (2017). Epidemiology and outcomes of people with dementia, delirium, and unspecified cognitive impairment in the general hospital: prospective cohort study of 10,014 admissions. BMC medicine, 15(1), 1-12.

Sadock, B. J., Sadock, V. A., \& Ruiz, P. (2015). Synopsis of psychiatry: behavioral sciences, clinical psychiatry. Wolters Kluwer.

Sastroasmoro, S., \& Ismael, S. (2011). Dasar-dasar metodologi penelitian klinis. Jakarta: sagung seto, 55.

Schwartz, T. L., \& Masand, P. S. (2002). The role of atypical antipsychotics in the treatment of delirium. Psychosomatics, 43(3), 171-174. https://doi.org/10.1176/appi.psy.43.3.171

Seitz, D. P., \& Gill, S. S. (2009). Neuroleptic malignant syndrome complicating antipsychotic treatment of delirium or agitation in medical and surgical patients: case reports and a review of the literature. Psychosomatics, 50(1), 815. https://doi.org/10.1176/appi.psy.50.1.8

Serafim, R. B., Bozza, F. A., Soares, M., do Brasil, P. E. A., Tura, B. R., Ely, E. W., \& Salluh, J. I. (2015). Pharmacologic prevention and treatment of delirium in intensive care patients: a systematic review. Journal of critical care, 30(4), 799-807. https://doi.org/10.1016/j.jcrc.2015.04.005

Sergeev, V. A., Glukhov, A. A., Sorokin, A. S., Zhuchkov, S. A., Gorokhov, A. V., \& Troshkina, E. N. (2021). Clinical-functional and morphological parameters of purulonecrotic foci healing in diabetic foot syndrome using programmable sanitation technologies. International Journal of Health Sciences, 5(3), 260-275. https://doi.org/10.53730/ijhs.v5n3.1495

Thom, R. P., Levy-Carrick, N. C., Bui, M., \& Silbersweig, D. (2019). Delirium. American Journal of Psychiatry, 176(10), 785-793.

Velásquez-Tirado, J. D., Trzepacz, P. T., \& Franco, J. G. (2021). Etiologies of Delirium in Consecutive COVID-19 Inpatients and the Relationship Between Severity of Delirium and COVID-19 in a Prospective Study With Follow-Up. The Journal of Neuropsychiatry and Clinical Neurosciences.

Vilke, G. M., Payne-James, J., \& Karch, S. B. (2012). Excited delirium syndrome (ExDS): redefining an old diagnosis. Journal of forensic and legal medicine, 19(1), 7-11. https://doi.org/10.1016/j.jflm.2011.10.006 
Wan, M., \& Chase, J. M. (2017). Delirium in older adults: Diagnosis, prevention, and treatment. British Columbia Medical Journal, 59(3).

Witlox, J., Eurelings, L. S., de Jonghe, J. F., Kalisvaart, K. J., Eikelenboom, P., \& Van Gool, W. A. (2010). Delirium in elderly patients and the risk of postdischarge mortality, institutionalization, and dementia: a metaanalysis. Jama, 304(4), 443-451.

Zipser, C. M., Deuel, J., Ernst, J., Schubert, M., Weller, M., von Känel, R., \& Boettger, S. (2019). Predisposing and precipitating factors for delirium in neurology: a prospective cohort study of 1487 patients. Journal of neurology, 266(12), 3065-3075. 